\title{
AUMC Over Dosing Interval Normalized by Body Mass Index
}

National Cancer Institute

\section{Source}

National Cancer Institute. AUMC Over Dosing Interval Normalized by Body Mass Index. NCI Thesaurus. Code C92338.

The area under the first moment curve (AUMC) for the defined interval between doses (TAU) divided by the body mass index. 